difficult to see in what respect it is inferior for this purpose to the expensive platinum-iridium alloy now in use.

The alloy could readily be made into laboratory vessels, cooking utensils, spoons, forks, etc., and it is limited in this respect only by its cost.

Cost.--Regarding the cost of production and manufacture, I am not at present prepared to make definite statements. I have succeeded, however, not only in obtaining the raw material at lower prices, but have also reduced the cost of production to a considerable degree, so that it is now possible to produce the alloys with as much despatch and precision as is possible in the production of common alloys.

Kокомо, IND.

\section{THE DETERMINATION OF SUGAR LOST BY EN- TRAINMENT FROM EVAPORATORS.}

\author{
BY R. S. NORRIS. \\ Received A ugust 5, 1910,
}

Wherever evaporating apparatus that was constructed twenty years or more ago is in use in sugar factories, there is likely to be a continual loss, more or less, of sugar by entrainment. It was only about that time that the importance of having large vapor pipes and considerable space above the steam chest or tubes was beginning to be realized. Even recently constructed evaporators may also entrain at certain times. Some reliable method of determining how much sugar is being lost in this way is therefore of importance.

In a multiple effect evaporator the entrainment is most pronounced from the last body, on account of the greater volume of the vapor and the greater viscosity of the juice. And as whatever juice is carried out with the vapor from this effect finds its way into the condenser water, it becomes necessary to determine the sugar in a very dilute solution and to know the weight of the solution, that is, of the condenser water. Various devices have also been used for collecting' a sample of the vapor, leaving the last effect representing an aliquotic portion of it, and determining the sugar in this; but these are of doubtful value.

As no detailed description of a method for determining the sugar in the condenser water is known to the writer, he has thought it advisable to publish a description of a method used by him in testing a number of evaporators.

The apparatus necessary for the determination is a stove or heater of some kind that can evaporate a considerable volume of water in a short time, a large vessel for evaporating the water in a small evaporating dish holding about two hundred cubic centimeters, a piece of sheet asbestos about eight inches (20 cm.) square, a measuring cylinder or flask holding five hundred cubic centimeters or a liter, a centigrade thermometer, and the usual sugar laboratory outfit for polarizations.

Five liters of condenser water are collected, a liter at a time, at intervals of half an hour, as it leaves the condenser and as near to it as possible, and placed in a perfectly clean vessel-preferably one that has not had anything containing sugar in it before. The evaporation had best be begun as soon as the first sample is collected, a few drops of sodium carbonate solution being first added. When the water has been evaporated down to about $\mathrm{I} 5 \mathrm{O} \mathrm{cc}$. it is transferred to the small evaporating dish, the last traces being washed out of the large dish into the smaller one.

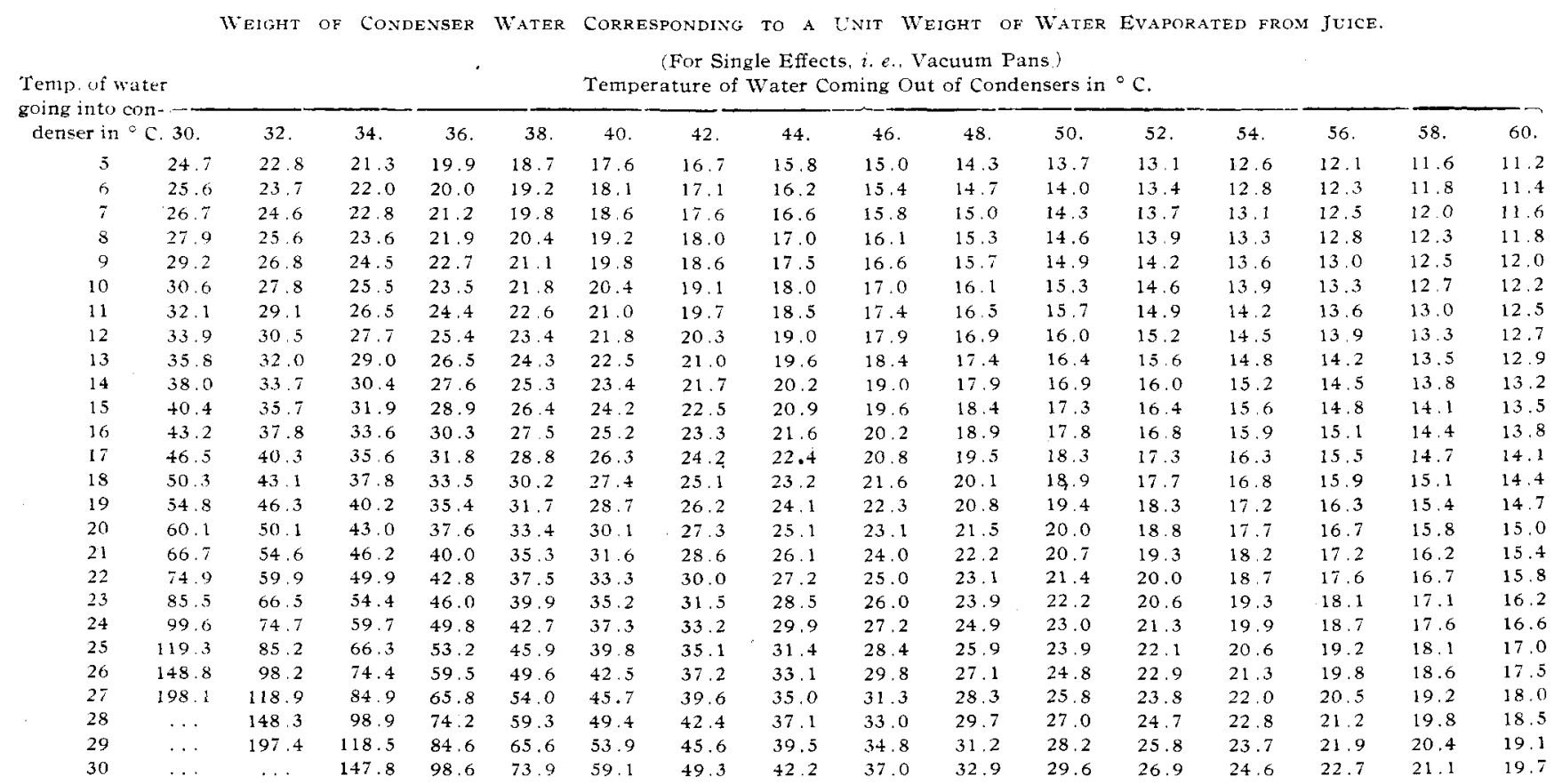


Weight of Condenser Water Corresponding to a Unit Weight of Water Evaporated from JUICE.

(For Double Effects.)

\begin{tabular}{|c|c|c|c|c|c|c|c|c|c|c|c|c|c|c|c|c|}
\hline \multirow{2}{*}{$\begin{array}{l}\text { Temp. of water } \\
\text { going into con- } \\
\text { denser in }{ }^{\circ} \mathrm{C} \text {. }\end{array}$} & \multicolumn{16}{|c|}{ Temperature of water coming out of condenser in ${ }^{\circ} \mathrm{C}$. } \\
\hline & 3) & 32. & 34. & 36. & 38. & 40. & 42. & 44. & 46. & 48. & 50. & 52. & 54. & 56. & 58. & 60. \\
\hline 5 & 13.2 & 12.2 & 11.3 & 10.6 & 10.0 & 9.4 & 8.9 & 8.4 & 8.0 & 7.6 & 7.3 & 7.0 & 6.7 & 6.5 & 6.2 & 6.0 \\
\hline 6 & 13.7 & 12.6 & 11.7 & 10.9 & 10.3 & 9.7 & 9.1 & 8.6 & 8.2 & 7.8 & 7.5 & 7.2 & 6.9 & 6.6 & 6.3 & 6.1 \\
\hline 7 & 14.3 & 13.1 & 12.1 & 11.3 & 10.6 & 9.9 & 9.4 & 8.9 & 8.4 & 8.0 & 7.6 & 7.3 & 7.0 & 6.7 & 6.4 & 6.2 \\
\hline 8 & 14.9 & 13.6 & 12.6 & 11.7 & 10.9 & 10.2 & 9.6 & 9.1 & 8.6 & 8.2 & 7.8 & 7.4 & 7.1 & 6.8 & 6.6 & 6.3 \\
\hline$q$ & 15.6 & 14.2 & 13.1 & 12.1 & 11.3 & 10.5 & 9.9 & 9.3 & 8.8 & 8.4 & 8.0 & 7.6 & 7.3 & 7.0 & 6.7 & 6.4 \\
\hline 10 & 16.3 & 14.8 & 13.6 & 12.5 & 11.7 & 10.9 & 10.2 & 9.6 & 9.1 & 8.6 & 8.2 & 7.8 & 7.4 & 7.1 & 6.8 & 6.5 \\
\hline 11 & 17.2 & 15.5 & 14.2 & 13.0 & 12.1 & 11.2 & 10.5 & 9.9 & 9.3 & 8.8 & 8.4 & 8.0 & 7.6 & 7.2 & 6.9 & 6.6 \\
\hline 12 & 18.1 & 16.3 & 14.8 & 13.5 & 12.5 & 11.6 & 10.8 & 10.2 & 9.6 & 9.0 & 8.6 & 8.1 & 7.7 & 7.4 & 7.1 & 6.8 \\
\hline 13 & 19.1 & 17.1 & 15.5 & 14.1 & 13.0 & 12.0 & 11.2 & 10.5 & 9.8 & 9.3 & 8.8 & 8.3 & 7.9 & 7.6 & 7.2 & 6.9 \\
\hline 14 & 20,3 & 18.0 & 16.2 & 14.7 & 13.5 & 12.5 & 11.6 & 10.8 & 10.1 & 9.5 & 9.0 & 8.5 & 8.1 & 7.7 & 7.4 & 7.1 \\
\hline 15 & 21.6 & 19.0 & 17.0 & 15.4 & 14.1 & 12.9 & 12.0 & 11.2 & 10.4 & 9.8 & 9.2 & 8.7 & 8.3 & 7.9 & 7.5 & 7.2 \\
\hline 16 & 23.1 & 20.2 & 17.9 & 16.2 & 14.7 & 13.5 & 12.4 & 11.5 & 10.7 & 10.1 & 9.5 & 9.0 & 8.5 & 8.3 & 7.7 & 7.3 \\
\hline 17 & 24.8 & 21.5 & 19.0 & 17.0 & 15.4 & 14.0 & 12.9 & 11.9 & 11,1 & 10.4 & 9.8 & 9.2 & 8.7 & 8.3 & 7.9 & 7.5 \\
\hline 18 & 26.8 & 23.0 & 20.1 & 17.9 & 16.1 & 14.6 & 13.4 & 12.4 & 11.5 & 10.7 & 10.1 & 9.5 & 8.9 & 8.5 & 8.1 & 7.7 \\
\hline 19 & 29.1 & 24.7 & 21.4 & 18.9 & 16.9 & 15.3 & 14.0 & 12.9 & 11.9 & 11.1 & 10.4 & 9.7 & 9.2 & 8.7 & 8.2 & 7.8 \\
\hline 20 & 32.1 & 26.8 & 22.9 & 20.1 & 17.8 & 16.1 & 14.6 & 13.4 & 12.3 & 11.5 & 10.7 & 10.0 & 9.4 & 8.9 & 8.4 & 8.0 \\
\hline 21 & 35.6 & 29.1 & 24.7 & 21.4 & 18.8 & 16.9 & 15.3 & 13.9 & 12.8 & 11.9 & 11.1 & 10.3 & 9.7 & 9.2 & 8.7 & 8.2 \\
\hline 22 & 40.0 & 32.0 & 26.7 & 22.9 & 20.0 & 17.8 & 16.0 & 14.5 & 13.3 & 12.3 & 11.4 & 10.7 & 10.0 & 9.4 & 8.9 & 8.4 \\
\hline 23 & 45.6 & 35.5 & 29.0 & 24.6 & 213 & 18.8 & 16.8 & 15.2 & 13.9 & 12.8 & 11.8 & .11 .0 & 10.3 & 9.7 & 9.1 & 8.6 \\
\hline 24 & 53.2 & 39.9 & 31.9 & 26.6 & 22.8 & 19.9 & 17.7 & 15.9 & 14.5 & 13.3 & 12.2 & 11.4 & 10.6 & 10.0 & 9.4 & 8.9 \\
\hline 25 & 63.7 & 45.5 & 35.4 & 28,9 & 24.5 & 21.2 & 18.7 & $16.8^{*}$ & 15.2 & 13.8 & 12.7 & 11.8 & 11.0 & 10.3 & 9.6 & 9.1 \\
\hline 26 & 79.5 & 53.0 & 39.7 & 31.8 & 26.5 & 22.7 & 19.9 & 17.7 & 15.9 & 14.4 & 13.2 & 12.2 & 11.4 & 10.6 & 9.9 & 9.3 \\
\hline 27 & $\ldots$ & 63.5 & 45.3 & 35.1 & 28.8 & 24.4 & 21.2 & 18.7 & 16.7 & 15.1 & $13: 8$ & 12.7 & 11.8 & 10.9 & 10.2 & 9.6 \\
\hline 28 & $\ldots$ & 79.2 & 52.8 & 39.6 & 31.7 & 26.4 & 22.6 & 19.8 & 17.6 & 15.8 & 14.4 & 13.2 & 12.2 & 11.3 & 10.6 & 9.9 \\
\hline 29 & $\ldots$ & $\ldots$ & 63.3 & 44.7 & 35.0 & 28.7 & 24.3 & 21.1 & 18.6 & 16.6 & 15.1 & 13.7 & 12.6 & 11.7 & 10.9 & 10.2 \\
\hline 30 & $\ldots$ & $\ldots$ & 78.9 & 52.6 & 39.5 & 31.6 & 26.3 & 22.6 & 19.7 & 17.5 & 15.8 & 14.3 & 13.1 & 12.1 & 11.3 & 10.5 \\
\hline
\end{tabular}

Weight of CONDENSER Water CORREsponding to A UNIT Weight of Water Evaporated from Juice.

(For Triple Effect.)

\begin{tabular}{|c|c|c|c|c|c|c|c|c|c|c|c|c|c|c|c|c|}
\hline Temp, of water & & & & & & & at & wate & ming & tof $c$ & nser & & & & & \\
\hline denser in ${ }^{\circ} \mathrm{C}$. & 32. & 32. & 34. & 36. & 38. & 40 & 42 . & 44. & 46. & 48 & 50. & 52. & 54. & 56. & 58. & 60. \\
\hline 5 & 9.1 & 8.4 & 7.9 & 7.4 & 6.5 & 6.5 & 6.2 & 5.8 & 5.6 & 5.3 & 4.9 & 4.9 & 4.7 & 4.5 & 4.3 & 4.2 \\
\hline 6 & 9.5 & 8.7 & 8.1 & 7.6 & 7.1 & 6.7 & 6.3 & 6.0 & 5.7 & 5.4 & 5.2 & 5.0 & 4.7 & 4.6 & 4.4 & 4,2 \\
\hline 7 & 9.9 & 9.1 & 8.4 & 7.8 & 7.3 & 6.9 & 6.5 & 6.1 & 5.8 & 5.5 & 5.3 & 5.1 & 4.8 & 4.6 & 4.5 & 4.3 \\
\hline 8 & 10.3 & 9.5 & 8.7 & 8.1 & 7.6 & 7.1 & 6.7 & 6.3 & 6.0 & 5.7 & 5.4 & 5.2 & 4.9 & 4.7 & 4.5 & 4.4 \\
\hline 9 & 10.8 & 9.9 & 9.1 & 8.4 & 7.8 & 7.3 & 6.9 & 6.5 & 6.1 & 5.8 & 5.5 & 5.3 & 5.0 & 4.8 & 4.6 & 4.4 \\
\hline 10 & 11.3 & 10.3 & 9.4 & 8.7 & 8.1 & 7.5 & 7.1 & 6.7 & 6.3 & 6.0 & 5.7 & 5.4 & 5.1 & 4.9 & 4.7 & 4.5 \\
\hline 11 & 11.9 & 10.8 & 9.8 & 9.0 & 8.4 & 7.8 & 7.3 & 6.8 & 6.5 & 6.1 & 5.8 & 5.5 & 5.3 & 5.0 & 4.8 & 4.6 \\
\hline 12 & 12.5 & 11.3 & 10.2 & 9.4 & 8.7 & 8.1 & 7.5 & 7.0 & 6.6 & 6.3 & 5.9 & 5.6 & 5.4 & 5.1 & 4.9 & 4.7 \\
\hline 13 & 13.2 & 11.8 & 10.7 & 9.8 & 9.0 & 8.3 & 7.8 & 7.3 & 6.8 & 6.4 & 6.1 & 5.8 & 5.5 & 5.2 & 5.0 & 4.8 \\
\hline 14 & 14.0 & 12.5 & 11.2 & 10.2 & 9.4 & 6.6 & 8.0 & 7.5 & 7.0 & 6.6 & 6.2 & 5.9 & 5.6 & 5.4 & 5.1 & 4.9 \\
\hline 15 & 15.0 & 13.2 & 11.8 & 10.7 & 9.8 & 9.0 & 8.3 & 7.7 & 7.2 & 6.8 & 6.4 & 6.1 & 5.8 & 5.5 & 5.2 & 5.0 \\
\hline 16 & 16.0 & 14.0 & 12.4 & 11.2 & 10.2 & 9.3 & 8.6 & 8.0 & 7.5 & 7.0 & 6.6 & 6.2 & 5.9 & 5.6 & 5.3 & 5.1 \\
\hline 17 & 17.2 & 14.9 & 13.2 & 11.8 & 10.6 & 9.7 & 8.9 & 8.3 & 7.7 & 7.2 & 6.8 & 6.4 & 6.0 & 5.7 & 5.5 & 5.2 \\
\hline 18 & 18.6 & 15.9 & 14.0 & 12.4 & 11.2 & 10.1 & 9.3 & 8.6 & 8.0 & 7.4 & 7.0 & 6.6 & 6.2 & 59 & 5.6 & 5.3 \\
\hline 19 & 20.3 & 17.1 & 14.9 & 13.1 & 11.7 & 10.6 & 9.7 & 8.9 & 8.3 & 7.7 & 7.2 & 6.8 & 6.4 & 6.0 & 5.7 & 5.4 \\
\hline 20 & 22.2 & 18.5 & 15.9 & 13.9 & 12.4 & 11.1 & 10.1 & 9.3 & 8.6 & 8.0 & 7.4 & 7.0 & 6.5 & 6.2 & 5.9 & 5.6 \\
\hline 21 & 24.7 & 20.2 & 17.1 & 14.8 & 13.1 & 11.7 & 10.6 & 9.7 & 8.9 & 8.2 & 7.7 & 7.2 & 6.7 & 6.4 & 6.0 & 5.7 \\
\hline 22 & 27.7 & 22.2 & 18.5 & 15.8 & 13,9 & 12.3 & 11.1 & 10.1 & 9.2 & 8.5 & 7.9 & 7.4 & 6.9 & 6.5 & 6.2 & 5.8 \\
\hline 23 & 31.6 & 24.6 & 20.1 & 17.0 & 14.8 & 13.0 & 11.7 & 10.5 & 9.6 & 8.9 & 8.2 & 7.6 & 7.2 & 6.7 & 6.3 & 6.0 \\
\hline 24 & 36.8 & 27.6 & 22.1 & 18.4 & 15.8 & 13.8 & 12.3 & 11.1 & 10.1 & 9.2 & 8.5 & 7.9 & 7.4 & 6.9 & 6.5 & 6.1 \\
\hline 25 & 44.1 & 31.5 & 24.5 & 20.1 & 17.0 & 14.7 & 13.0 & 11.6 & 10.5 & 9.6 & 8.8 & 8.2 & 7.6 & 7.1 & 6.7 & 6.3 \\
\hline 26 & 55.1 & 36.7 & 27.5 & 22.0 & 18.4 & 15.7 & 13.8 & 12.2 & 11.0 & 10.0 & 9.2 & 8.5 & 7.9 & 7.4 & 6.9 & 6.5 \\
\hline 27 & 73.3 & 44.0 & 31.4 & 24.4 & 20.0 & 16.9 & 14.7 & 12.9 & 11.6 & 10.5 & 9.6 & 8.8 & 8.2 & 7.6 & 7.1 & 6.6 \\
\hline 28 & $\ldots$ & 54.9 & 36.6 & 27.4 & 22.0 & 18.3 & 15.7 & 13.7 & 12.2 & 11.0 & 10.0 & 9.2 & 8.6 & 7.9 & 7.3 & 6.9 \\
\hline 29 & $\cdots$ & $\cdots$ & 43.8 & 31.3 & 24.3 & 19.9 & 16.9 & 14,6 & 12.9 & 11.5 & 10.4 & 9.5 & 8.8 & 8.1 & 7.6 & 7.1 \\
\hline 30 & & $\ldots$ & 54.7 & 36.5 & 27,4 & 21.9 & 18.2 & 15.6 & 13.7 & 12.2 & 11.0 & 10.0 & 9.1 & 8.4 & 7.8 & 7.3 \\
\hline
\end{tabular}

The small dish is placed on the stove over the sheet of asbestos with a two and a half-inch $(6 \mathrm{~cm}$.) hole in it. The evaporation is continued until only about 75 cc. remain-it is not safe to go beyond this on account of the risk of decomposing some of the sugar. The solution is then transferred to a Ioo $\mathrm{cc}$. sugar flask, about I cc. of lead subacetate solution and a little aluminum cream added, made up to I Io $\mathrm{cc}$, filtered and polarized. The polarization of the solution can be found from Schmitz's table, taking the first reading on the left in the table. To find the polarization of the condenser water from this, divide by fifty, since the water was evaporated to one-fiftieth of its original volume.

For instance, suppose the polariscope reading were 3.0 , the $100 \mathrm{cc}$. of evaporated solution would then have a polarization of 0.85 and the original condenser water a polarization of 0.017 .

In order to interpret this in pounds of sugar lost in condenser water per day, it is only necessary to know the weight of condenser water. This can be calculated from the volume measured with a weir, or it can be found in terms of the weight of juice by taking the temperature of the water going in and 
Wetght of Condenser Water Corresponding to a tinit Weight of Water Evaporated from Juice.

(For Quadruple Effects.)

\begin{tabular}{|c|c|c|c|c|c|c|c|c|c|c|c|c|c|c|c|c|}
\hline \multirow{2}{*}{$\begin{array}{l}\text { Temp. of water } \\
\text { going into con- } \\
\text { denser in }{ }^{\circ} \mathrm{C} \text {. }\end{array}$} & \multicolumn{16}{|c|}{ Temperature of water coming out of condenser in ${ }^{\circ} \mathrm{C}$. } \\
\hline & 30. & 32. & 34. & 36. & 38. & 40 . & 42. & 44. & 46. & 48 & 50. & 52. & 54 & 56. & 58. & 60. \\
\hline 5 & 7.0 & 6.5 & 6.0 & 5.6 & 5.3 & 5.0 & 4.7 & 4.5 & 4.3 & 4.1 & 3.9 & 3.7 & 3.6 & 3.4 & 3.3 & 3.2 \\
\hline 6 & 7.3 & 6.7 & 6.2 & 5.8 & 5.5 & 5.1 & 4.9 & 4.6 & 4.4 & 4.2 & 4.0 & 3.8 & 3.6 & 3.5 & 3.4 & 3.2 \\
\hline 7 & 7.6 & 7.0 & 6.5 & 6.0 & 5.6 & 5.3 & 5.0 & 4.7 & 4.5 & 4.3 & 4.1 & 3.9 & 3.7 & 3.6 & 3.4 & 3.3 \\
\hline 8 & 7.9 & 7.3 & 6.7 & 6.2 & 5.8 & 5.4 & 5.1 & 4.8 & 4.6 & 4.4 & 4.1 & 4.0 & 3.8 & 3.6 & 3.5 & 3.3 \\
\hline 9 & 8.3 & 7.6 & 7.0 & 6.4 & 6.0 & 5.6 & 5.3 & 5.0 & 4.7 & 4.5 & 4.2 & 4.0 & 3.9 & 3.7 & 3.6 & 3.4 \\
\hline 10 & 8.7 & 7.9 & 7.2 & 6.7 & 6.2 & 5.8 & 5.4 & 5,1 & 4.8 & 4.6 & 4.3 & 4.1 & 3.9 & 3.8 & 3.6 & 3.5 \\
\hline 11 & 9.1 & 8.3 & 7.5 & 6.9 & 6.4 & 6.0 & 5.6 & 5.3 & 5.0 & 4.7 & 4.4 & 4.2 & 4.0 & 3.9 & 3.7 & 3.5 \\
\hline 12 & 9.3 & 8.7 & 7.9 & 7.2 & 6.7 & 6.2 & 5.8 & 5.4 & 5.1 & 4.8 & 4.6 & 4.3 & 4.1 & 3.9 & 3.8 & 3.6 \\
\hline 13 & 10.2 & 9.1 & 8.2 & 7.5 & 6.9 & 6.4 & 6.0 & 5.6 & 5.2 & 4.9 & 4.7 & 4.4 & 4.2 & 4.0 & 3.8 & 3.7 \\
\hline 14 & 10.8 & 9.6 & 8.6 & 7.8 & 7.2 & 6.6 & 6.2 & 5.7 & 5.4 & 5.1 & 4.8 & 4.5 & 4.3 & 4.1 & 3.9 & 3.7 \\
\hline 15 & 11.5 & 10.1 & 9.1 & 8.2 & 7.5 & 6.9 & 6.4 & 5,9 & 5.6 & 5.2 & 4.9 & 4.7 & 4.4 & 4.2 & 4.0 & 3.8 \\
\hline 16 & 12.3 & 10.7 & 9.6 & 8.6 & 7.8 & 7.2 & 6.6 & 6.1 & 5.7 & 5.4 & 5.1 & 4.8 & 4.5 & 4.3 & 4.1 & 3,9 \\
\hline 17 & 13.2 & 11.4 & 10.1 & 9.0 & 8.2 & 7.5 & 6.9 & 6.4 & 5.9 & 5.5 & 5.2 & 4.9 & 4.6 & 4.4 & 4.2 & 4.0 \\
\hline 18 & 14.3 & 12.2 & 10.7 & 9.5 & 8.6 & 7.8 & 7.1 & 6.6 & 6.1 & 5.7 & 5.4 & 5,0 & 4.8 & 4.5 & 4.3 & 4.1 \\
\hline 19 & 15.6 & 13.2 & 11.4 & 10.1 & 9.0 & 8.1 & 7.4 & 6.8 & 6.3 & 5.9 & 5.5 & 5.2 & 4.9 & 4.6 & 4.4 & 4.2 \\
\hline 20 & 17,1 & 14.2 & 12.2 & 10.7 & 9.5 & 8.5 & 7.8 & 7.1 & 6.6 & 6.1 & 5.7 & 5.3 & 5.0 & 4.7 & 4.5 & 4.3 \\
\hline 21 & 18.9 & 15.5 & 13.1 & 11,4 & 10.0 & 9.0 & 8.1 & 7.4 & 6.8 & 6.3 & 5.9 & 5.5 & 5.2 & 4.9 & 4.6 & 4.4 \\
\hline 22 & 21.3 & 17.0 & 14.2 & 12.2 & 10.6 & 9.5 & 8.5 & 7.7 & 7.1 & 6.5 & 6.1 & 5.7 & 5.3 & 5.0 & 4.7 & 4.5 \\
\hline 23 & 24.3 & 18.9 & 15.4 & 13.1 & 11.3 & 10.0 & 8.9 & 8.1 & 7.4 & 6.8 & 6.3 & 5.9 & 5.5 & 5.1 & 4.9 & 4.6 \\
\hline 24 & 28.3 & 21.2 & 17.0 & 14.1 & 12.1 & 10.6 & 9.4 & 8.5 & 7.7 & 7.1 & 6.5 & 6.1 & 5.7 & 5.3 & 5.0 & 4.7 \\
\hline 25 & 33.9 & 24.2 & 18.8 & 15.4 & 13.0 & 11.3 & 10.0 & 8.9 & 8.1 & 7.4 & 6.8 & 6.3 & 5.8 & 5.5 & 5.1 & 4.8 \\
\hline 26 & 42.3 & 28.2 & 21.1 & 16,9 & 14.1 & 12.1 & 10.6 & 9.4 & 8.5 & 7.7 & 7.0 & 6.5 & 6.0 & 5.6 & 5.3 & 5.0 \\
\hline 27 & 56.3 & 3.3 .8 & 24,1 & 18.7 & 15.3 & 13.0 & 11.3 & 9.9 & 8.9 & 8.0 & 7.3 & 6.8 & 6.3 & 5.8 & 5.4 & 5.1 \\
\hline 28 & $\ldots$ & 42.2 & 28.1 & 21.1 & 16.9 & 14.0 & 12.0 & 10.5 & 9.4 & 8. 4 & 7.7 & 7.0 & 6.5 & 6.0 & 5.6 & 5.3 \\
\hline 29 & $\ldots$ & $\ldots$ & 33.6 & 24.0 & 18.6 & 15.3 & 12.9 & 11.2 & 9.9 & 8.9 & 8.0 & 7.3 & 6.7 & 6.2 & 5.8 & 5.4 \\
\hline 30 & $\ldots$ & $\ldots$ & 42.0 & 28.0 & 21.0 & 16.8 & 14.0 & 12.0 & 10.5 & 9.3 & 8.4 & 7.6 & 7.0 & 6.5 & 6.0 & 5.6 \\
\hline
\end{tabular}

Weight of Condenser Water Corresponding to a Unit Weight of Water Evaporated from Juice.

(For Quintuple Effects.)

Temp. of water. Temperature of water coming out of condenser in ${ }^{\circ} \mathrm{C}$.

\begin{tabular}{|c|c|c|c|c|c|c|c|c|c|c|c|c|c|c|c|c|}
\hline denser in ${ }^{\circ} \mathrm{C}$. & 30. & 32. & 34. & 36. & 38. & 40 & 42. & 44 & 46. & 48 & 50 & 52. & 54. & 56. & 58. & 60. \\
\hline 5 & 5.8 & 5.4 & 5.0 & 4.7 & 4.4 & 4.1 & 3.9 & 3.7 & 3.5 & 3.4 & 3.2 & 3.1 & 3.0 & 2.8 & 2.7 & 2.6 \\
\hline 6 & 6.0 & 5.6 & 5.2 & 4.8 & 4.5 & 4.3 & 4.0 & 3.8 & 3.6 & 3.4 & 3.3 & 3.1 & 3.0 & 2.9 & 2.8 & 2.7 \\
\hline 7 & 6.3 & 5.8 & 5.3 & 5.0 & 4.7 & 4.4 & 4.1 & 3.9 & 3.7 & 3.5 & 3.4 & 3.2 & 3.1 & 3.0 & 2.8 & 2.7 \\
\hline 8 & $6: 6$ & 6.0 & 5.5 & 5.1 & 4.8 & 4.5 & 4.2 & +.0 & 3.8 & 3.6 & 3.4 & 3.3 & 3.1 & 3.0 & 2.9 & 2.8 \\
\hline 9 & 6.9 & 6.3 & 5.8 & 5.3 & 5.0 & 4.6 & 4.4 & 4.1 & 3.9 & 3.7 & 3.5 & 3.3 & 3.2 & $3 \cdot 1$ & 2.9 & 2.8 \\
\hline 10 & 7.2 & 6.5 & 6.0 & 5.5 & 5.1 & 4.8 & 4.5 & 4.2 & 4.0 & 3.8 & 3.6 & 3.4 & 3.3 & 3.1 & 3.0 & 2.9 \\
\hline 11 & 7.5 & 6.8 & 6.2 & 5.7 & 5.3 & 4.9 & 4.6 & 4.3 & 4.1 & 3.9 & 3.7 & 3.5 & 3.3 & 3.2 & 3.1 & 2.9 \\
\hline 12 & 8.0 & 7.2 & 6.5 & 6.0 & 5.5 & 5.1 & 4.8 & 4.5 & 4.2 & 4.0 & 3.8 & 3.6 & 3.4 & 3.3 & 3.1 & 3.0 \\
\hline 13 & 8,4 & 7.5 & 6.8 & 6.2 & 5.7 & 5.3 & 4.9 & 4.6 & 4.3 & 4.1 & 3.9 & 3.7 & 3.5 & 3.3 & 3,2 & 3.0 \\
\hline 14 & 8.9 & 7.9 & 7.1 & 6.5 & 5.9 & 5.5 & 5.1 & 4.8 & 4.5 & 4.2 & 4.0 & 3.8 & 3.6 & 3.4 & 3.2 & 3.1 \\
\hline 15 & 9.5 & 8.4 & 7.5 & 6.8 & 6.2 & 5.7 & 5.3 & 4.9 & 4.6 & 4.3 & 4.1 & 3.9 & 3.7 & 3.5 & 3.3 & 3.2 \\
\hline 16 & 10.2 & 8.9 & 7.9 & 7.1 & 6.5 & 5.9 & 5.5 & 5.1 & 4.7 & 4.4 & 4.2 & 4.0 & 3.7 & 3.6 & 3.4 & 3.2 \\
\hline 17 & 10.9 & 9.5 & 8.4 & 7.5 & 6.8 & 6.2 & 5.7 & 5.3 & 4.9 & 4.6 & 4.3 & 4.1 & 3.8 & 3.6 & 3.5 & 3.3 \\
\hline 18 & 11.8 & 10.1 & 8,9 & 7.9 & 7.1 & 6.4 & 5.9 & 5.5 & 5.1 & 4.7 & 4.4 & +.2 & 3.9 & 3.7 & 3.5 & 3.4 \\
\hline 19 & 12.9 & 10.9 & 9.4 & 8.3 & 7.5 & 6.7 & 6.2 & 5.7 & 5.2 & 4.9 & 4.6 & 4.3 & 4.0 & 3.8 & 3.6 & 3.5 \\
\hline 20 & 14.1 & 11.8 & 10,1 & 8,8 & 7.9 & 7.1 & 6.4 & 5.9 & 5.4 & . 5.0 & 4.7 & 4.4 & 4.2 & 3.9 & 3.7 & 3.5 \\
\hline 21 & 15.7 & 12.8 & 10.9 & 9.4 & 8.3 & 7.4 & 6.7 & 6.1 & 5.6 & 5.2 & 4.9 & 46 & 4.3 & 4.0 & 3.8 & 3.6 \\
\hline 22 & 17.6 & 14,1 & 11.7 & 10.1 & 8.8 & 7.8 & 7.0 & 6.4 & 5.9 & 5.4 & 5.0 & 4.7 & 4.4 & 4.1 & 3.9 & 3.7 \\
\hline 23 & 20.1 & 15.6 & 12.8 & 10.8 & 9.4 & 8.3 & 7.4 & 6.7 & 6.1 & 5.6 & 5.2 & 4.8 & 4.5 & 4.3 & 4.0 & 3.8 \\
\hline 24 & 23.4 & 17.5 & 14.0 & 11.7 & 10.0 & 8.8 & 7.8 & 7.0 & 6.4 & 5.8 & 5.4 & 5.0 & 4.7 & 4.4 & 4.1 & 3.9 \\
\hline 25 & 28.0 & 20.0 & 15.6 & 12.7 & 10.8 & 9.3 & 8.2 & 7.4 & 6.7 & 6.1 & 5.6 & 5.2 & 4.8 & 4.5 & 4.2 & 4.0 \\
\hline 26 & 35.0 & 23.3 & 17.5 & 14.0 & 11.7 & 10.0 & 8.7 & 7.8 & 7.0 & 6.4 & 5.8 & 5,4 & 5.0 & 4.7 & 4.4 & 4.1 \\
\hline 27 & 46.6 & 27.9 & 20.0 & 15.5 & 12.7 & 10.7 & 9.3 & 8.2 & 7.4 & 6.7 & 6.1 & 5.6 & 5.2 & 4.8 & 4.5 & 4.2 \\
\hline 28 & $\ldots$ & 34.9 & 23.2 & 17.4 & 13.9 & 11.6 & 10.0 & 8.7 & 7.7 & 7.0 & 6.3 & 5.8 & 5.4 & 5.0 & 4.6 & 4.4 \\
\hline 29 & $\ldots$ & $\ldots$ & 27.8 & 19.9 & 15.4 & 12.7 & 10.7 & 9.3 & 8.2 & 7.3 & 6.6 & 6.1 & 5.6 & 5.2 & 4.8 & 4.5 \\
\hline 30 & $\ldots$ & $\ldots$ & 34.7 & 23.2 & 17.4 & 13.9 & 11.6 & 9.9 & 8.7 & 7.7 & 6.9 & 6.3 & 5.8 & 5.3 & 5.0 & 4.6 \\
\hline
\end{tabular}

coming out of the condenser with a centigrade thermometer, and referring to the accompanying tables, which give the weight of condenser water corresponding to unit weight of water evaporated from the juice. And this number multiplied by the percentage evaporation, calculated from the formula

Per cent. evaporation (by weight) $=$

Brix of Evaporated Juice-Brix of Thin Juice, Brix of Evaporated Juice

gives the weight of condenser water corresponding to unit weight of juice entering evaporator. ${ }^{1}$ This

1 For convenince this may be taken to be equal to the weight of diffusion juice or mixed juice, which is usually known. result, multiplied by the weight of mixed juice or diffusion juice for twenty-four hours, gives the weight of condenser water per day, from which the weight of sugar in the condenser water for one day can be calctlated directly, by multiplying by its polarization as found above. For example, with a triple effect, suppose we have:

$$
\begin{aligned}
& \text { Temperature of water going into condenser..... } 20^{\circ} \mathrm{C} \text {. } \\
& \text { Temperature of water coming out of condenser } \ldots, 42^{\circ} \mathrm{C} \text {. } \\
& \text { Brix of clarified or thin juice } \ldots \ldots \ldots \ldots \ldots \ldots \ldots, 14.7 \\
& \text { Brix of syrup or thick juice...... } \\
& \text { Weight of mixed juice or diffusion juice in one day. } 500 \text { tons }
\end{aligned}
$$

Using these figures, we find from the table that there are IO. I pounds of condenser water for each 
pound of water evaporated from the juice. The evaporation calculated from the formula is 76.3 per cent. We therefore have 10. I $\times 0.763=7.7$ pounds of condenser for each pound of juice. And since the diffusion, or mixed juice weighs $1,000,000$ pounds, the condenser water will weigh $\mathrm{r}, 000,000 \times$ $7 \cdot 7=7,700,000$ pounds and contain $7,700,000 \times$ $0.00017=1309$ pounds of sugar per day.

The tables were calculated from the formulas ${ }^{1}$

in which

$$
\text { (I) } \mathrm{W}_{a}=\frac{w\left(c-t_{b}\right)}{t_{b}-t_{a}}, \text { (II) } \mathrm{W}_{b}=\left(\mathrm{W}_{a}+\mathrm{I}\right) \mathrm{E} \text {, }
$$

$\mathrm{W}_{a}=$ weight of injection water going into condenser; $\mathrm{W}_{b}=$ weight of water coming out of condenser;

$w=$ weight of vapor from last body;

$c=$ total heat of unit weight of vapor from last body, in calories;

$t_{a}=$ temperature in ${ }^{\circ} \mathrm{C}$. of injection water going into condenser;

$t_{b}=$ temperature in ${ }^{\circ} \mathrm{C}$. of water coming out of condenser;

$\mathrm{E}^{\prime}=$ average per cent. evaporation in last body.

In calculating the tables the factor $c$ is taken equal to $62 \mathrm{I} .3$, which is the total heat of unit weight of steam under a vacuum of 25 inches. The corresponding factors at other pressures are:

$\begin{array}{cc}\text { Inches. } & \text { Calories. } \\ 22 & 625.9 \\ 23 & 624.4 \\ 24 & 623.1 \\ 26 & 619.5 \\ 27 & 616.8 \\ 28 & 613.4\end{array}$

For the factor $\mathrm{E}$ the following numbers were used in the calculations:

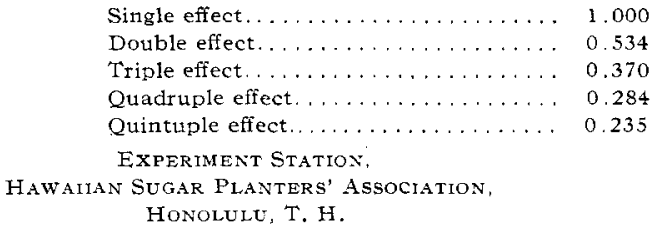

\section{AN ACCURATE METHOD FOR CALORIMETRIC DETERMINATIONS ON ANTHRACITE COAL.}

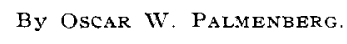

As I have been called upon during the past year to make a considerable number of calorimetric determinations on anthracite coals and using an Atwater-Mahler calorimeter in all my work, it was necessary to find some convenient, reliable and accurate method to burn these coals, as it is a well-known fact that anthracite coals do not burn readily in the oxygen bomb calorimeter. No matter how finely the coal is pulverized, it is very seldom that a complete combustion can be obtained, and although I have been able to make duplicate tests which agreed very

1 For a discussion of formula I see E Hausbrand "Evaporating, Condensing and Cooling Apparatus,"p, 212 , well, in many cases, the calorimetric determinations were low and it would be necessary to filter the bomb washings and burn the residue in a Gooch crucible and from this loss in weight correct for the unburned coal. Such a method is not alone inaccurate, but requires too much time where many tests a day are to be run. The combustion in the bomb became less complete the greater the ash content. It occurred to me that the coal would have to be mixed with some material that would assist combustion and burn up this small amount of coal which was invariably left in the bomb washings. I first tried to make a pellet by mixing pulverized cane sugar with the coal and succeeded in getting rather concordant results this way from a mixture of I gram of sugar and 0.5 gram coal, but this method had its fault and was not very satisfactory.

Next I tried to enclose the coal (about 0.5 gram) in a gelatine capsule, but never succeeded in obtaining complete combustion; at least not with very high ash coals; and besides, gelatine being so hygroscopic, errors would occur in the weighings.

The only satisfactory and simple method I have found which gives absolutely complete combustion is to weigh out 0.2 gram of semi-bituminous coal of about $\mathrm{I} 4300$ to $\mathrm{I} 4500$ B. t. u. in a shallow nickel capsule ( $\mathrm{r}$ in. $\mathrm{x}_{3} / 8 \mathrm{in}$.) which fits in the supports in the bomb conveniently, and after spreading this soft coal evenly over the bottom of the capsule, weigh on top of this 0.8 gram of the anthracite coal, pulverized to pass a roo mesh. A little more or less in weight of either coal does not affect the result, so long as the quantity taken has been accurately weighed. This weighing can be done in a very short time and there is nothing more to do but to have the wire touch the coal, whereupon the combustion will be complete and tests can be made as accurately as on any soft coal.

It is only necessary to know the calorific content and the amount of sulphur in the kindler (soft coal) burned, whereupon the correction for these is applied very conveniently. I keep a four-ounce bottle of stock coal which has been passed through a 60mesh sieve and thoroughly mixed and from this draw a small specimen tube full, which tube full will last for about 50 determinations.

My stock bottle of coal was put up June 4, I909, and calorimetric tests were made from time to time to make sure of the corrections and the following results were obtained:

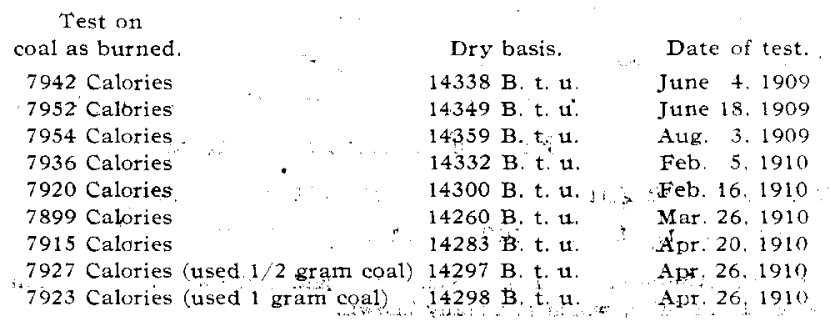

